СЕЛЬСКОХОЗЯЙСТВЕННЫЕ НАУКИ

\title{
SOIL CLASSIFICATION HAS YET TO BE CREATED
}

Рожков Вячеслав Александрович

DOI: $10.31618 / \mathrm{asj} .2707-9864.2020 .1 .37 .4$

Abstract. The thesis is put forward that all the classifications of soils existing in the world do not possess the attributes of such a concept accepted in science and its technical applications but are only lists of author's names of soils. The names are substantiated mainly by factors of soil formation (natural zoning, vegetation, series, etc.), on weakly reasoned genetic horizons and small unformalized aggregates of soil properties. At the Soil Institute Named After V.V. Dokuchaev of the Russian Academy of Science, a mathematical apparatus for the development and use of digital soil classifications was created.

Key words: classification attributes, existing soil classifications, digital classification.

The most important problems of world soil science are soil classifications, which are considered the philosophy and language of science. However, the existing diverse structures describing national and international sets of soils, strictly speaking, are not classifications. These are nothing more than lists of names of soils arranged in a certain order: by natural zones, vegetation, series, etc. Further research of such structures is aimed at finding new soils, additional indicators, and clarifying the intervals of their values. The necessary provisions of the scientific concept of classifications are not used: indicators of similarity soil differences, evaluations of the information content of attributes, quality criteria and comparison of classifications, formal rules for recognizing new soils, etc. Higher school: scientific research. The existing soil classifications from Sibirtsev to Soil Taxonomy are lists of soils by natural zones, series, etc. These lists of soils should be considered as the source material for creating these classifications. They are absolutely necessary for understanding the real diversity of soil profiles and taking into account the opinions of different scientists and practitioners, determining soil characteristics for the subsequent formation of the required attributes of formalized classifications. A meta-algorithm for constructing a formal classification of soils as an addition and completion of traditional constructions was developed. The meta-algorithm software includes software modules that have been tested over many years of use in solving real problems. A hierarchical or ordinate classification based on equivalence classes is provided. At the same time, evaluations of the information content of attributes are new, calculations of similarity-differences between objects and classes, a weighted pair-group criterion of grouping by the principle of "nearest neighbor" are formalized. For the first time, criteria for the quality of classifications and their comparison with each other were used. Recognition of new soils is carried out by discriminant analysis and/or by the values of the similarity of their descriptions with established objects. Numerical classification methods (multivariate statistics and cluster analysis) allow us to solve these problems. The result of their application is a "digital" classification of soils. At the same time, it is a question of formalizing the creation, analysis and use of classifications by introducing mathematical methods, and traditional lists are the source material for constructing classifications. 